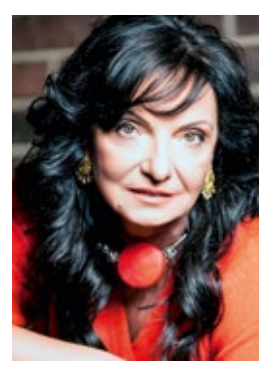

Т.В. Пав^ова

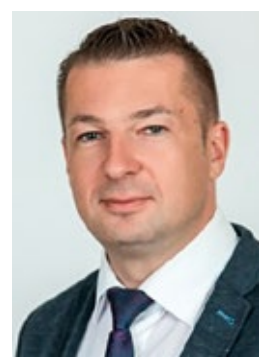

К.И. Прощаев

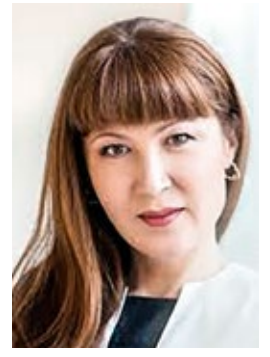

Э.Е. Сатардинова

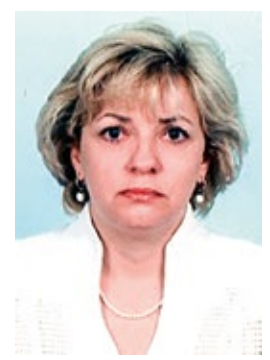

Н.Б. Пи^ькевич

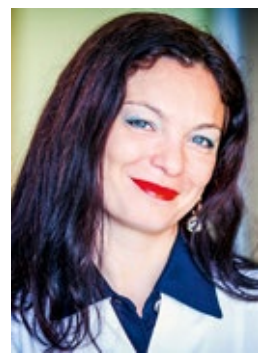

^. А. Пав^ова

Оценка тревожно-депрессивных расстройств и показателей качества жизни у женщин пожилого возраста

Т. В. Павлова, А.М.Н., профр., зав. кафельрой патологии'

К.И. Прощаев, А.М.Н., профр., $\Delta и р е к т о p^{2}$

Э. Е. СатарАинова, К.М.Н., АОцент кафеАры рефрлексотерапии и косметологии ${ }^{3}$

Н.Б. Пимькевич, А.М.Н., профр. кафредры патологии'

^.А. Павлова, А.м.Н., профр. кафелры патологии'

'ФГАОУ ВО «БелгороАСКИЙ госуАарственный национальный исслеАОвательсКИй университет», г. БелгороА

${ }^{2}$ АНО «Научно-исслеАовательский меАицинский центр „Геронтология“"), г. Москва

'Иркутская государственная меАицинская акалемия послеАипломного образования, г. Иркутск, Россия

\title{
Assessment of anxiety-depressive disorders and quality of life indicators in elderly women
}

T. V. Pavlova, K.I. Proshchayev, E. E. Satardinova, N. B. Pilkevich, L. A. Pavlova

Belgorod State National Research University, Belgorod; 'Gerontology' Scientific Research Medical Centre, Moscow; Irkutsk State Medical Academy of Postgraduate Education, Irkutsk; Russia

\section{Резюме}

Цель. Оценить тревожно-Аепрессивные расстройства и показатели качества жизни у женщин пожилого возрас та. Материалы и методы. В исследование было включено 540 женщин с нарушениями гормонамьного фона в виАе преАКАимактерического иАи кАимактерического синАрома: 270 женщин в возрасте 44-54 лет (среАний возраст $49,1 \pm 2,2$ гоАа), из них 150 женщин с «-» и 120 с «+» вариантом биологического возраста, и 270 женщин в возрасте 55-64 лет (среАний возраст 57,2 $\pm 2,4$ гоАа), из них 150 с ॥-) и 120 человек с ॥+॥ вариантом биологического возраста. Все пациенты в зависимости от предлагаемого варианта нутритивной поААержки и физической активности были разАелены на три группы: первая (стандартные рекоменАации), вторая (станАартные рекоменАации, сканАинавская хоАьба и ежеАневные прогулки не менее 30 минут) и третья (станАартные рекоменАации, скандинавская хоАьба, ежеАневные прогулки не менее 30 минут и нутритивная подАержка). Оценка степени Аепрессии проводилась по шкале Бека. Качество жизни опреАелялось по шкале-опроснику SF-36 Health Status Surveу, визуально-аналоговой шкале А^я оценки тревожно-Аепрессивного синарома. Результаты. По шкале оценки уровня Аепрессии, уровня тревожно-Аепрессивного синдрома у женщин были получены Аанные о Аостоверном улучшении этого показателя при применении нутритивной поААержки и физической активности. Максимальная разница была отмечена у Аиц старшего возраста с ॥-» и ॥+» вариантом биологического возраста. По шкале оценки уровня психологического зАоровья у женщин нами быми получены Аанные об улучшении этого показателя при применении нутритивной поААержки и физической активности, ОАнако АОстоверная разница была обнаружена только по сравнению с пациентами, не получавшими ни нутритивной подАержки, ни физической активности. Зак^ючение. Применение нутритивной поААержки и физической активности у женщин пожилого возраста улучшает параметры качества жизни особенно по уровню общего зАоровья, степени депрессии и уровню социального функционирования.

КАючевые слова: женщины, качество жизни, пожилой возраст, тревожно-Аепрессивный синдром.

\section{Summary}

Objective. To assess anxiety-depressive disorders and indicators of quality of life in elderly women. Materials and methods. The study included 540 women with hormonal disorders in the form of a premenopausal or menopausal syndrome: 270 women, aged 44-54 years (mean age $49.1 \pm 2.2$ ), of whom 150 women with '-' and 120 with ' + ' variant of the biological age and 270 women aged 55-64 years (mean age $57.2 \pm 2.4$ ), of which 150 with '-' and 120 people with 't' version of biological age. All patients, depending on the proposed variant of nutritional support and physical activity, were divided into three groups: the 1st (standard recommendations), the 2nd (standard recommendations, scandinavian walking and daily walks for at least 30 minutes), the 3rd (standard recommendations, scandinavian walking, daily walks for at least 30 minutes and nutritional support). Assessment of the degree of depression was carried out on the basis of the Beck scale. The quality of life was determined by the SF-36 Health Status Survey, a visual analogue scale for assessing the anxiety-depressive syndrome. Results. On the scale of assessing the level of depression, the level of anxiety-depressive syndrome in women, data were obtained on a reliable improvement of this indicator with the use of nutritional support and physical activity. The maximum difference was noted in older persons with '-' and '+' variant of biological age. On the scale of assessing the level of psychological health in women, we obtained data on improving this indicator with nutritional support and physical activity, but a significant difference was found only in comparison with patients who received neither nutritional support nor physical activity. Conclusion. The use of nutritional support and physical activity in elderly women improves the parameters of quality of life, especially in terms of general health, depression and social functioning.

Key words: women, quality of life, elderly age, anxiety-depressive syndrome. 


\section{Введение}

По данным ВО3, за период с 2015 по 2050 год число людей в возрасте 60 лет и старше возрастет с 900 млн до 2 млрд (с 12 до $22 \%$ общей численности населения мира). По прогнозам, к 2050 году число пожилых людей, нуждающихся в поддержке в повседневной жизни, в развивающихся странах возрастет в четыре раза [1]. Термин «качество жизни» (QoL или LQ) приобретает все большее признание и используется в формировании гуманистической социальной политики и решении ее проблем в связи с необходимостью адаптации человека к изменившимся условиям существования при старении, появлении и прогрессировании заболеваний, свойственных старости [2]. Происходит возрастание значения понятия «качество жизни» для людей пожилого и старческого возраста [3-5].

В свою очередь, директор Российского геронтологического научноклинического центра Минздрава РФ, академик РАН В.Н. Шабалин относит изучение роли качества жизни пожилых людей в формировании здоровья к числу приоритетных направлений фундаментальных и прикладных научных исследований [6].

Процесс старения человека сопровождается ухудшением всех форм нейропсихической деятельности, что связано с уменьшением массы головного мозга и его дегенеративно-дистрофическими изменениями [7]. Как следствие происходит ухудшение всех форм нейропсихической деятельности. Частота возникновения адинамии, сонливости и депрессивных состояний возрастает за счет снижения синтеза биологически активных веществ [7]. Согласно литературным данным, симптомы тревоги и депрессии наблюдаются у 25-30\% лиц старше 65 лет, на фоне сопутствующей соматической патологии эта цифра достигает 50\% [5], это приводит к снижению показателей качества жизни $[5,7,8]$.

\section{Материалы и методы}

Всего в наше исследование было включено 540 женщин. Всем пациентам определялся биологический возраст (БВ) - его позитивный («+») и негативный («-») варианты. Нега- тивный вариант БВ свидетельствует о признаках преждевременного старения. Пациенты с нормальным вариантом БВ в исследование включены не были. Группы подбирались однородные в течение 5 лет для объективизации данных исследования.

Bce обследуемые нами пациенты были распределены следующим образом: из 540 женщин с нарушениями гормонального фона в виде предклимактерического или климактерического синдрома - 270 человек в возрасте 44-54 лет (средний возраст $49,1 \pm 2,2$ года), из них 150 человек с «-» и 120 с «+» вариантом БВ, и 270 женщин в возрасте 55-64 лет (средний возраст 57,2 $\pm 2,4$ года), из них 150 человек с «-» и 120 человек с «+» вариантом БВ.

Bce пациенты в зависимости от предлагаемого варианта нутритивной поддержки и физической активности были разделены на три группы:

- первая группа (контрольная) пациенты получали стандартные рекомендации врача без нутритивной поддержки и режима физической активности;

- вторая группа - дополнительно к стандартным рекомендациям пациенты занимались аэробными видами тренировок в виде скандинавской ходьбы (два раза в неделю по 60 минут под руководством инструктора) и ежедневных прогулок продолжительностью не менее 30 минут, без нутритивной поддержки;

- третья группа - дополнительно к стандартным рекомендациям пациенты занимались аэробными видами тренировок в виде скандинавской ходьбы (два раза в неделю по 60 минут под руководством инструктора), ежедневных прогулок продолжительностью не менее 30 минут с нутритивной поддержкой в виде приема Nutridrink Compact Protein по одной порции три раза в день и Resurs ${ }^{\circledR} 2,0$ + Faiber по одной порции три раза в день.

В каждую из групп было включено по 90 женщин в возрасте 45-54 лет (40 с «+» и 50 с «-» вариантом БВ) и 90 женщин в возрасте 55-64 лет (40 с «+» и 50 с «-» вариантом БВ).
Оценка степени депрессии проводилась по шкале Бека [9], тревожнодепрессивный синдром оценивался по визуально-аналоговой шкале.

Качество жизни определялось по российской версии стандартного вопросника, разработанного John E. Ware, SF 36 Health Status Survey [10]. В его основе лежат субъективная оценка пациентом своего физического и психического здоровья, а также удовлетворенность и общее благополучие. Опросник MOS SF-36 является распространенной краткой формой оценки здоровья, которая не ограничена гендерными и возрастными особенностями, соматической патологией и спецификой лечения. Данный метод исследования делает возможным изучение и сопоставление уровня качества жизни как неспецифического, так и специфического контингента.

Анкета включает в себя 11 пунктов с вопросами и вариантами ответа, которые группируют восемь шкал. Их количественная оценка характеризует 10 основных критериев (показателей) физического и психического здоровья. Числовой диапазон результатов исследования по каждой из шкал находится в пределах от 0 до 100, причем чем выше оценка, тем выше уровень качества жизни. При этом физический компонент здоровья отражает в себе четыре других показателя: физическое и ролевое функционирование, интенсивность боли и общее состояние здоровья. Психический компонент здоровья формируют остальные четыре показателя: социальное и ролевое функционирование, жизненная активность и психическое здоровье (см. схему).

В основе статистических методов обработки данных лежал метод статистических регистров с динамической рандомизацией по исследуемым признакам. При этом в нашей работе при обработке данных исследования был проведен расчет средних абсолютных и относительных величин с расчетом ошибки средней; выполнена оценка значимости различий двух совокупностей с применением критерия t Стьюдента (разность показателей считалась достоверной при $\mathrm{t}>2 ; \mathrm{p}<0,05)$. 


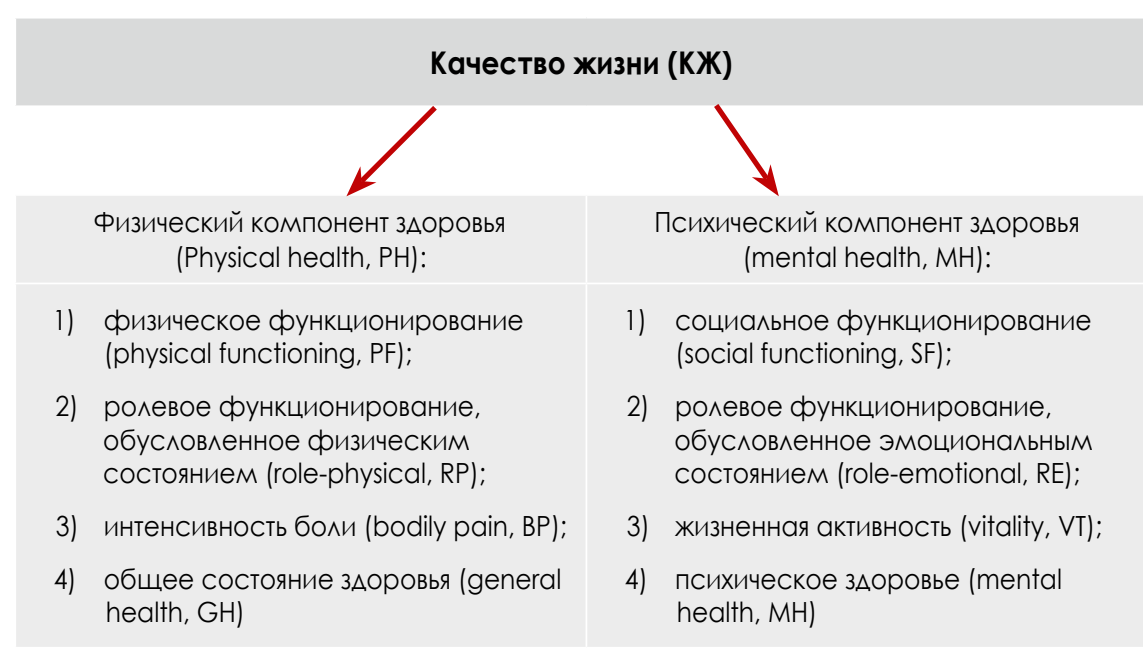

Схема. Опросник MOS SF-36.

\section{Результаты}

Нами была проведена оценка показателей качества жизни, уровня депрессии и тревожно-депрессивного синдрома в группах наблюдения (см. табл.). Оценка общего здоровья у женщин имела особенности.

Так, у женщин в возрасте 45 54 лет при «+» варианте БВ в первой группе было выявлено 66,1 \pm 1,1 балла при оценке общего здоровья, во второй группе - 74,0 \pm 0,7 балла, $\mathrm{p}<$ 0,05 - достоверные различия между показателями первой и второй групп, в третьей группе - 83,4 $\pm 1,4$ балла, $\mathrm{p}<0,05$ - достоверные различия между показателями второй и третьей групп; $\mathrm{p}<0,05$ - достоверные различия между показателями первой и третьей групп. Таким образом, в группе, где применялась физическая активность и нутритивная поддержка, у пациентов с «+» вариантом БВ были обнаружены максимальные значения оценки общего здоровья (см. табл.).

У женщин в возрасте 45-54 лет при «-» варианте БВ в первой группе было выявлено 59,6 \pm 0,3 балла при оценке общего здоровья, во второй группе $68,2 \pm 1,4$ балла, $\mathrm{p}<0,05$ - достоверные различия между показателями первой и второй групп, $\mathrm{p}<0,05$ по сравнению с показателем «+» вариант БВ одного возраста, в третьей группе - 83,0 $\pm 1,1$ балла, $\mathrm{p}<0,05$ - достоверные различия между показателями второй и третьей групп; $\mathrm{p}<0,05$ - достоверные различия между показателями первой и третьей групп, $\mathrm{p}>$ 0,05 по сравнению с показателем «+» вариант БВ одного возраста.
У женщин в возрасте 55-64 лет при «+» варианте БВ в первой группе было выявлено 54,1 \pm 2,2 балла при оценке общего здоровья, во второй группе - 55,2 $\pm 2,1$ балла, $\mathrm{p}>0,05-$ недостоверные различия между показателями первой и второй групп, в третьей группе - 66,8 $\pm 1,6$ балла, $\mathrm{p}<0,05$ - достоверные различия между показателями второй и третьей групп; $\mathrm{p}<0,05$ - достоверные различия между показателями первой и третьей групп, $\mathrm{p}<0,05$ по сравнению с показателем «+» вариант БВ другой возрастной группы. Таким образом, в группе пациентов в возрасте 55-64 года, где применялись физическая активность и нутритивная поддержка, у пациентов с «+» вариантом БВ были обнаружены минимальные значения оценки общего здоровья среди аналогичных групп (см. табл.).

У женщин в возрасте 55-64 лет при «-» варианте БВ в первой группе было выявлено 48,1 \pm 1,2 балла при оценке общего здоровья, $\mathrm{p}<0,05$ по сравнению с показателем «-» вариант БВ разного возраста, во второй группе - 52,2 $\pm 2,1$ балла, $\mathrm{p}>0,05-$ достоверные различия между показателями первой и второй групп, $\mathrm{p}<$ 0,05 по сравнению с показателем «-» вариант БВ разного возраста, в третьей группе - 79,8 \pm 1,6 балла, $\mathrm{p}<0,05-$ достоверные различия между показателями второй и третьей групп; $\mathrm{p}<$ 0,05 - достоверные различия между показателями первой и третьей групп, p > 0,05 по сравнению с показателем «+» вариант БВ одного возраста.
По шкале оценка общего здоровья у женщин нами были получены данные о значительном достоверном улучшении этого показателя при применении нутритивной поддержки и физической активности. Максимальная разница была отмечена у женщин старшего возраста с «-» вариантом БВ. Достоверной разницы между пациентами молодого возраста третьей группы с «+» и «-» БВ достигнуто не было. Данные, приведенные в таблице, подтверждают факт, что нутритивная поддержка улучшает параметры общего здоровья.

Оценка уровня депрессии по шкале Бека у женщин показала следующее (см. табл.).

У женщин в возрасте 45-54 лет при «+» варианте БВ в первой группе было выявлено 45,2 \pm 2,8 балла при оценке уровня депрессии, во второй группе - 58,1+0,3 балла, $\mathrm{p}<0,05-$ достоверные различия между показателями первой и второй групп, в третьей группе - 77,0 \pm 1,3 балла, $\mathrm{p}<$ 0,05 - достоверные различия между показателями второй и третьей групп; $\mathrm{p}<0,05$ - достоверные различия между показателями первой и третьей групп. Таким образом, в группе, где применялись физическая активность и нутритивная поддержка, у пациентов с «+» вариантом БВ были обнаружены достоверные максимальные положительные значения по оценке уровня депрессии.

У женщин в возрасте 45-54 лет при «-» варианте БВ в первой группе было выявлено $36,6 \pm 2,8$ балла при оценке уровня депрессии, во второй группе - 59,1 $\pm 1,1$ балла, $\mathrm{p}<0,05$ достоверные различия между показателями первой и второй групп, $\mathrm{p}<$ 0,05 по сравнению с показателем «+» вариант БВ одного возраста, в третьей группе - 85,2 $\pm 2,1$ балла, $\mathrm{p}<0,05$ достоверные различия между показателями второй и третьей групп; $\mathrm{p}<$ 0,05 - достоверные различия между показателями первой и третьей групп, $\mathrm{p}<0,05$ по сравнению с показателем «+» вариант БВ одного возраста.

У женщин в возрасте 55-64 лет при «+» варианте БВ в первой группе было выявлено 41,2 $\pm 3,1$ балла при оценке уровня депрессии, во второй группе - 63,3 $\pm 2,1$ балла, $\mathrm{p}<$ 
Таблица

\begin{tabular}{|c|c|c|c|c|}
\hline \multirow{2}{*}{ Группа } & \multicolumn{2}{|c|}{ Женщины 45-54 лет (n = 90) } & \multicolumn{2}{|c|}{ Женщины 55-64 лет (n = 90) } \\
\hline & ॥+» вариант БВ $(n=40)$ & ॥-॥) вариант БВ $(n=50)$ & ॥+») вариант БВ $(n=40)$ & ॥-П) вариант БВ $(n=50)$ \\
\hline \multicolumn{5}{|c|}{ Общее зАоровье } \\
\hline $1-9$ & $66,1 \pm 1,1$ & $59,6 \pm 0,3 *$ & $54,1 \pm 2,2 * *$ & $48,1 \pm 1,2^{* * *}$ \\
\hline $2-9$ & $74,0 \pm 0,71-2$ & $68,2 \pm 1,41-2$ & $55,2 \pm 2,1^{* *}$ & $52,2 \pm 2,1^{* * *}$ \\
\hline $3-9$ & $83,4 \pm 1,41-3,2-3$ & $83,0 \pm 1,11-3,2-3$ & $66,8 \pm 1,6 * *, 1-3,2-3$ & $79,8 \pm 1,61-3,2-3$ \\
\hline \multicolumn{5}{|c|}{ Оценка уровня Аепрессии по шкале Бека } \\
\hline $1-9$ & $45,2 \pm 2,8$ & $36,6 \pm 2,8^{*}$ & $41,2 \pm 3,1$ & $34,4 \pm 2,3^{*}$ \\
\hline $2-9$ & $58,1 \pm 0,31-2$ & $59,1 \pm 1,11-2$ & $63,3 \pm 2,1 \quad 1-2$ & $62,2 \pm 3,1$ \\
\hline $3-9$ & $77,0 \pm 1,32-3,1-3$ & $85,2 \pm 2,1 *, 2-3,1-3$ & $75,2 \pm 3,12-3,1-3$ & $86,3 \pm 2,1^{*}, 2-3,1-3$ \\
\hline \multicolumn{5}{|c|}{ Оценка тревожно-Аепрессивного синдрома } \\
\hline $1-9$ & $48,4 \pm 1,1$ & $47,4 \pm 1,1$ & $45,3 \pm 2,0$ & $38,2 \pm 1,3^{*}, * * *$ \\
\hline $2-9$ & $55,1 \pm 1,61-2$ & $58,1 \pm 1,61-2$ & $59,2 \pm 1,71-2$ & $57,8 \pm 1,81-2$ \\
\hline $3-9$ & $66,9 \pm 2,21-3,2-3$ & $67,9 \pm 2,21-3,2-3$ & $68,9 \pm 2,02-3,1-3$ & $68,6 \pm 1,52-3,1-3$ \\
\hline $1-9$ & $68,2 \pm 1,7$ & $67,3 \pm 1,4$ & $67,3 \pm 2,0$ & $67,2 \pm 2,0$ \\
\hline $2-9$ & $71,2 \pm 2,8$ & $70,2 \pm 2,4$ & $70,1 \pm 2,4$ & $70,4 \pm 2,4$ \\
\hline 3-я & $74,2 \pm 3,91-3$ & $75,2 \pm 2,51-3$ & $73,1 \pm 1,21-3$ & $74,1 \pm 1,21-3$ \\
\hline \multicolumn{5}{|c|}{ Ролевое эмоциональное функционирование } \\
\hline $1-9$ & $65,2 \pm 1,9$ & $65,8 \pm 1,9$ & $62,2 \pm 1,8$ & $64,2 \pm 1,8$ \\
\hline $2-9$ & $66,4 \pm 1,9$ & $66,0 \pm 1,9$ & $65,2 \pm 1,9$ & $66,2 \pm 2,5$ \\
\hline $3-9$ & $69,4 \pm 2,1$ & $72,2 \pm 2,81-3$ & $68,2 \pm 1,91-3$ & $73,2 \pm 3,01-3$ \\
\hline \multicolumn{5}{|c|}{ Социальное функционирование } \\
\hline $1-9$ & $63,1 \pm 2,8$ & $62,1 \pm 2,8$ & $61,4 \pm 1,8$ & $60,3 \pm 2,1$ \\
\hline $2-9$ & $81,6 \pm 3,01-2$ & $79,6 \pm 3,01-2$ & $79,4 \pm 3,01-2$ & $81,2 \pm 3,01-2$ \\
\hline 3-9 & $88,5 \pm 2,82-3,1-3$ & $97,5 \pm 3,2 *, 2-3,1-3$ & $88,9 \pm 2,82-3,1-3$ & $98,1 \pm 3,2 *, 2-3,1-3$ \\
\hline
\end{tabular}

Примечание: * - р <0,05 по сравнению с показателем «+» вариант БВ онного возраста; ** - р < 0,05 по сравнению с показателем «+» вариант БВ Аругой возрастной группы; ${ }^{* * *}-\mathrm{p}<0,05$ по сравнению с показателем «-» вариант БВ $А$ ругой возрастной группы; ${ }^{1-2}-$ р <0,05 -

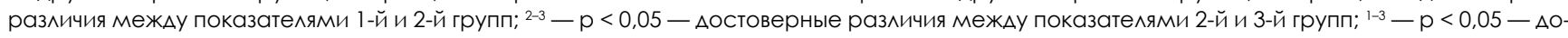
стоверные различия межау показателями 1-й и 3-й групп.

0,05 - достоверные различия между показателями первой и второй групп, в третьей группе - 75,2 $\pm 3,1$ балла, $\mathrm{p}<0,05$ - достоверные различия между показателями второй и третьей групп; $\mathrm{p}<0,05$ - достоверные различия между показателями первой и третьей групп, $\mathrm{p}>0,05$ по сравнению с показателем «+» вариант БВ другой возрастной группы. Таким образом, в группе пациентов в возрасте 55-64 года, где применялись физическая активность и нутритивная поддержка, у пациентов с «+» вариантом БВ были обнаружены наихудшие значения оценки уровня депрессии среди аналогичных групп.

У женщин в возрасте 55-64 лет при «-» варианте БВ в первой группе было выявлено 34,4 \pm 2,3 балла при оценке уровня депрессии, $\mathrm{p}<0,05$ по сравнению с показателем «-» вариант БВ разного возраста, во второй группе $62,2 \pm 3,1$ балла, $p>0,05$ - достоверные различия между показателями первой и второй групп, $\mathrm{p}<0,05$ по сравнению с показателем «-» вариант БВ разного возраста, в третьей группе - 86,3 $\pm 2,1$ балла, $\mathrm{p}<0,05$ - достоверные различия между показателями второй и третьей групп; $\mathrm{p}<0,05$ - достоверные различия между показателями первой и третьей групп, $\mathrm{p}>0,05$ по сравнению с показателем «+» вариант БВ одного возраста.

По шкале оценки уровня депрессии у женщин нами были получены данные о значительном достоверном улучшении этого показателя при применении нутритивной поддержки и физической активности. Максимальная разница была отмечена у лиц старшего возраста с «-» вариантом БВ, что подтверждает факт того, что нутритивная поддержка снижает уровень депрессии.

Как видно из таблицы, при оценке тревожно-депрессивного синдрома были получены результаты ниже, чем при оценке по шкале депрессии во всех исследуемых группах.

Так, у женщин в возрасте $45-$ 54 лет при «+» варианте БВ в пер- вой группе было выявлено 48,4 4 1,1 балла при оценке уровня тревожнодепрессивного синдрома, во второй группе - 55,1 \pm 1,6 балла, $\mathrm{p}<$ 0,05 - достоверные различия между показателями первой и второй групп, в третьей группе - 66,9 $\pm 2,2$ балла, $\mathrm{p}<0,05$ - достоверные различия между показателями второй и третьей групп; $\mathrm{p}<0,05$ - достоверные различия между показателями первой и третьей групп. Таким образом, в группе, где применялись физическая активность и нутритивная поддержка, у пациентов с «+» вариантом БВ были обнаружены достоверные положительные значения по оценке уровня тревожно-депрессивного синдрома.

У женщин в возрасте 45-54 лет при «-» варианте БВ в первой группе было выявлено 47,4 \pm 1,1 балла при оценке тревожно-депрессивного синдрома, во второй группе - 58,1 $\pm 1,6$ балла, $\mathrm{p}<0,05$ - достоверные различия между показателями первой 
и второй групп, $\mathrm{p}>0,05$ по сравнению с показателем «+» вариант БВ одного возраста, в третьей группе - 67,9 \pm 2,2 балла, $\mathrm{p}<0,05$ — достоверные различия между показателями второй и третьей групп; $\mathrm{p}<0,05-$ - достоверные различия между показателями первой и третьей групп, $\mathrm{p}>$ 0,05 по сравнению с показателем «+» вариант БВ одного возраста.

У женщин в возрасте 55-64 лет при «+» варианте БВ в первой группе было выявлено 45,3 \pm 2,0 балла при оценке тревожно-депрессивного синдрома, во второй группе - 59,2 \pm 1,7 балла, $\mathrm{p}<0,05$ - достоверные различия между показателями первой и второй групп, в третьей группе $68,9 \pm 2,0$ балла, $\mathrm{p}<0,05$ - достоверные различия между показателями второй и третьей групп; $\mathrm{p}<0,05-$ достоверные различия между показателями первой и третьей групп, p > 0,05 по сравнению с показателем «+» вариант БВ другой возрастной группы. Таким образом, в группе пациентов в возрасте 55-64 лет, где применялись физическая активность и нутритивная поддержка, у пациентов с «+» вариантом БВ были обнаружены наилучшие значения оценки уровня тревожно-депрессивного синдрома среди аналогичных групп (см. табл.).

У женщин в возрасте 55-64 лет при «-» варианте БВ в первой группе было выявлено 38,2 \pm 1,3 балла при оценке тревожно-депрессивного синдрома, $\mathrm{p}<0,05$ по сравнению с показателем «-» вариант БВ разного возраста, во второй группе - 57,8 \pm 1,8 балла, $\mathrm{p}>0,05$ - достоверные различия между показателями первой и второй групп, $\mathrm{p}<0,05$ по сравнению с показателем «-» вариант БВ разного возраста, в третьей группе - 68,6 \pm 1,5 балла, $\mathrm{p}<0,05-$ достоверные различия между показателями второй и третьей групп; $\mathrm{p}<0,05$ - достоверные различия между показателями первой и третьей групп, $\mathrm{p}>0,05$ по сравнению с показателем «+» вариант БВ одного возраста.

По шкале оценки уровня тревожно-депрессивного синдрома у женщин нами были получены данные о достоверном улучшении этого по- казателя при применении нутритивной поддержки и физической активности. Максимальная разница была отмечена у лиц старшего возраста с «-» и «+» вариантом БВ, что подтверждает факт того, что нутритивная поддержка улучшает параметры тревожно-депрессивного синдрома.

При оценке психологического здоровья у женщин с предклимактерическим и климатерическим синдромом нами были обнаружены достоверные различия только между группами, не получавшими ни физической активности, ни нутритивной поддержки (первая группа), и между группами, получавшими физическую активность и нутритивную поддержку (третья группа).

Как видно из таблицы, у женщин в возрасте 45-54 лет при «+» варианте БВ в первой группе было выявлено 68,2 $\pm 1,7$ балла при оценке уровня психологического здоровья, во второй группе - 71,2 $\pm 2,8$ балла, $\mathrm{p}>0,05$ - недостоверные различия между показателями первой и второй групп, в третьей группе - 74,2 \pm 3,9 балла, $\mathrm{p}>0,05$ - недостоверные различия между показателями второй и третьей групп; $\mathrm{p}<0,05-$ достоверные различия между показателями первой и третьей групп. У женщин в возрасте 45-54 лет при «-» варианте БВ в первой группе было выявлено $67,3 \pm 1,4$ балла при оценке психологического здоровья, во второй группе - 70,2 $\pm 2,4$ балла, $\mathrm{p}>0,05$ - недостоверные различия между показателями первой и второй групп, $\mathrm{p}>$ 0,05 по сравнению с показателем «+» вариант БВ одного возраста, в третьей группе - 75,2 \pm 2,5 балла, $\mathrm{p}>0,05$ - недостоверные различия между показателями второй и третьей групп; $\mathrm{p}<0,05$ - достоверные различия между показателями первой и третьей групп, $\mathrm{p}>$ 0,05 по сравнению с показателем «+» вариант БВ одного возраста.

У женщин в возрасте 55-64 лет при «+» варианте БВ в первой группе было выявлено 67,3 $\pm 2,0$ балла при оценке уровня психологического здоровья, во второй группе - 70,1 \pm 2,4 балла, $p>0,05$ - недостоверные различия между показателями первой и второй групп, в третьей группе - 73,1 $\pm 1,2$ балла, $\mathrm{p}>0,05$ недостоверные различия между показателями второй и третьей групп; $\mathrm{p}<0,05$ - достоверные различия между показателями первой и третьей групп, $\mathrm{p}>0,05$ по сравнению с показателем «+» вариант БВ другой возрастной группы. Таким образом, в группе пациентов в возрасте 55 64 лет, где применялись физическая активность и нутритивная поддержка, у пациентов с «+» вариантом БВ были обнаружены наилучшие значения оценки уровня психологического здоровья среди аналогичных групп, однако разница показателей достоверна только между первой и третьей группами и недостоверна между группами разного возраста и результатами БВ.

У женщин в возрасте 55-64 лет при «-» варианте БВ в первой группе было выявлено 67,2 \pm 2,0 балла при оценке уровня психологического здоровья, $\mathrm{p}>0,05$ по сравнению с показателем «-» вариант БВ разного возраста, во второй группе - 70,4 2,4 балла, $p>0,05$ - недостоверные различия между показателями первой и второй групп, $\mathrm{p}>0,05$ по сравнению с показателем «-» вариант БВ разного возраста, в третьей группе - 74,1 1,2 балла, $p>0,05$ - недостоверные различия между показателями второй и третьей групп; $\mathrm{p}<0,05$ - достоверные различия между показателями первой и третьей групп, $\mathrm{p}>0,05$ по сравнению с показателем «+» вариант БВ одного возраста.

По шкале оценки уровня психологического здоровья у женщин нами были получены данные об улучшении этого показателя при применении нутритивной поддержки и физической активности, однако достоверная разница была обнаружена только по сравнению с пациентами, не получавшими ни нутритивной поддержки, ни физической активности.

\section{Выводы}

Применение нутритивной поддержки и физической активности у женщин пожилого возраста улучшает параметры качества жизни, особенно по уровню общего здоровья, степени депрессии и уровню социального функционирования. 


\section{Список Аитературь}

1. Чирков В.А., Бреутов А. В., Бреутова Р.А. Социально-гигиеническое исслеАование качества жизни лиц пожилого возраста, проживающих в различных социальных условиях. Современные исслеАования социальных проблем (электронный научный журнал). 2012; 12 (20): www.sisp.nkras.ru.

2. Аворецкий А.И. Качество жизни пожилого человека. РуковоАство по геронтологии и ге риатрии: ВIV т. ПоА реА. акаА. РАМН, профо. В.Н. Ярыгина, проор. А.С. Мелентьева.T. II. Введение в клиническую гериатрию. Часть І. ГАава 11. М. 2005; 154-160.

3. Куликова Н.Г. Качество жизни населения в старших возрастных группах. Проблемь социальной гигиены, зАравоохранения и истории меАицины. 2005; 1: 12-13.

4. Малыхин Ф.Т. Качество жизни, обусловленное состоянием зАоровья Аиц пожилого и старческого возраста (обзор митературы). Качественная кАиническая практика. 201 1; 1: 11-18.

5. Капустенская Ж.И., Шпрах В.В., Зайцева О.И. Афрфоективные и конгитивные расстройства У ^иц пожилого И старческого возраста. Бюмметень ВСНЦ СО РАМН. 2010; 2 (72): 52-54

6. РУководство по геронтологии. ПоА реА. ака Аемика РАМН В.Н. Шабалина. М. 2005. 800 с.

7. Гусев Е.И., Ярыгин В.Н., Мишнев О.А. Особенности и семиотика мороро-фрункци ональных изменений нервной системы стареющего человека. Руководство по геРОНтологии и гериатрии: в IV т. ПОА РеА. акаА. РАМН, профр. В.Н. Ярыгина, профо. А. С. Мелентьева. Т. IV. КАиническая гериатрия. Часть І. ГАава 1. М. 2003; 15-19.

8. Малыхин Ф.Т. Проблемы качества жизни У пациентов старших возрастных групп. Медицинский вестник Северного Кавказа. 2012; 2: 96-101.

9. Beck A.T. et al. An Inventory for Measuring Depression //Archives of general psychiatry. 1961; 4 (6): 561-571.

10. John E., Ware J.E. SF-36 Health Survey Manua and Interpretation Guide. The Health Institute. New England Medical Center. Boston. Mass. 1993.

А^я цитирования. Павлова Т.В., Прощаев К.И., СатарАинова Э.Е., Пи^ькевич Н.Б., Пав^ова А.А. Оценка тревожно-Аепрессивных расстройств и показателей качества жизни у женшин пожилого возраста // Медицинский алфравит. Серия «Неврология и психиатрия».- 2019.— Т. 2 19 (394).- C. $42-47$

\section{В России стало Аоступным принципиально новое ^ечение АюАей с психическими расстройствами}

4 июня 2019 года формацевтическая компания «Гедеон Рихтер» объяви^а овывоАе на российский рынок своего инновационного препарата Аля леченияшизосррении. Совместно с Всероссийскимщентром изучения общественного мнения (ВцИОМ) она представила результаты опроса жителей страны об их освеАомленности о заболевании и отношении к пациентам, которые живут с таким Аиагнозом.

Согласно полученным Аанным 63\% опрошенных считают, что они не в состоянии контролировать болезнь, а $38 \%$ сказали, что таким ^ЮАям СтоИт находиться поАальше от большинства. СреАи проблем, с которыми сталкиваются пациенты, сложность с труАОустройством $(40 \%)$ и ^екарственным обеспечением (33\%). Новый антипсихотик, наА созАанием которого компания труди^ась почти 20 ^ет, призван принципиально изменить существующие подходы к ^ечению шизодррении и «вернуть» АюАей, которые живут с этим Аиагнозом, в социум.

Шизофррения - хроническое и инвалидизирующее психическое заболевание, Аля которого характерно нарушение мышления и восприятия. По статистике, им страдают около 1 \% населения планеты, ему в равной степени подвержены как мужчины, так и женщины. Симптомы заболевания Аелятся на три основных категории. Это позитивные: галмюцинации, бреА, умственные и лвигательные расстройства; и негативные: потеря мотивации, апатия, скуАность речи, асоциальность. ВыАеляют также когнитивную симптоматику: расстройства мышления, восприятия, памяти и внимания

Петр Морозов, А.М.Н., профрессор кафедры психиатрии фракультета Аополнительного просрессионального образования Российского национального исслеАовательского меАицинского университета имени Н.И. Пирогова подчеркивает: «Проблема пациентов, страдающих шизофренией в том, что они не осознают того, что больны. Они не понимают, что их заболевание - это огромное бремя как Аля них самих, так и Аля их родственников и общества в целом. Бремя, которое можно уменьшать за счет применения ^екарственной терапии. Аолгое время у нас в арсенале не было препаратов, которые воздействовали не только на позитивную, но и на негативную симптоматику, которая возникает у $60 \%$ пациентов и ведет к Аесоциализации пациентов. Кроме того, прежние терапевтические решения сопровожАались большим количеством побочных эфоректов. Появление нового препарата, который может оАновременно снимать и ту, и Аругую симптоматику, вызывает значительно меньшее количество нежелательных явлений, мы приветствуем, поскольку виАИм за этим значительное улучшение качества оказания меАищинской помощиџ.

Препарат, с которым связывают новые належАы пациентов и их родственников специалисты,- оригинальная разработка компании. За его созАание она получи^а национальный гран-при в области инноваций. Препарат уже пользуется значительным спросом в США, и вывеАен на рынки стран ЗапаАной и Восточной Европы.

Габор Орбан, генеральный Аиректор компании, отмечает: «Мы горАимся тем что мы - первая венгерская фрармацевтическая компания, чья разработка так востребована на мировом рынке. Теперь мы виАим, как наш препарат помогает многим пациентам с психическими расстройствами в США и Европе вернуться в социум. Мы чувствуем особое үАОвлетворение от того что можем значительно изменить К Аүчшему жизни милмионов АюАей с шизофренией и их родственников. Мы уверены, что наш фрлагманский продукт будет не менее востребован и в России - ОАНом из КАючевых рынков А^я компании „ГеАеон Рихтер"».

Говорит Аттила Варали, полномочный преАставитель компании «ГеАеон Рихтер» в России: «Мы продолжим совместную работу с меАицинским сообществом, сАе^аем все, что в наших силах, чтобы помочь и пациентам, и их родственникам. Уверен, что вместе мы изменим отношение общества к пациентам с особенностями развития, пси хическими расстройствами, слелаем его еще более толерантным».

Сог^асно полученным в результате исслеАования ВцИОМ Аанным среди проблем, с которыми сталкиваются пациенты с шизодренией, были названы труАности с трудоустройством (40\%), а также с лекарственным обеспечением (33\%). Причем среди тех, кто имеет родственников, страдающих этим заболеванием, этот процент выше

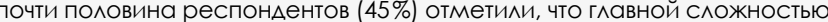
яв^яется именно возможность получить необходимые препараты. Не гатив со стороны общества (34\%) был также назван в числе трудностей, через которые проходят пациенты. И несмотря на то что большинство опрошенных россиян (52\%) не считают, что АюАям с шизодренией следует находиться подальше от остальных, все же более трети (38\%) говорят об обратном - изоляции таких пациентов.

Кири^^ Родин, Аиректор по работе с органами государственной в асти Всероссийского центра изучения общественного мнения утвержАает: «С социологической точки зрения, Аанное заболевание относится к стигматизированным общественным явлениям. Выражаясь проще, это метка, которая Аелает человека изгоем Аля значительной части обще ства. Каково основное социальное послеАствие этой проблемыट Ее ^окализация внутри отАеАьной семьи или личности, резкое сокращение

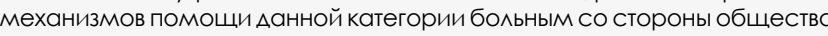
и проффилактики Аанного явления, что привоАит К НовЫМ опаснЫМ инци Аентам, связанным с асоциальными проявлениями и к еще большему усилению стигматизация заболевания. Как разорвать этот круг? Способ оАин: внимательное отношение со стороны общества к ^юдям, оказавШимся в труАной жизненной ситуации, повышение уровня инорормированности об этом заболевании ипомощь близКим и роАственникам тех КТо СТОАКнУАСя С поАОбным АИагнозом».

В результате опроса было также выявлено:

- $90 \%$ россиян знают о таком психическом расстройстве, как ши зоорения, причем $20 \%$ утвержАают, что хорошо знакомы с его симптомами;

- кажАый пятый (20\%) знает о АюАях с расстройством «Шизосррения) в своем окружении: у $4 \%$ есть родственники с таким расстройством еще $16 \%$ знакомы с больными шизофренией лично или знают о таком АИагнозе у кого-то из Арузей или роАСтвенников знакомых;

- по мнению опрошенных, большинство россиян Относятся К АюАям с психическими расстройствами так: с сочувствием (38\%), с жалостью (34\%), со страхом (26\%), с недоверием (18\%), с презрением (9\%)

- наиболее характерными признаками шизодрении, по мнению опрошенных, являются: сильные перемены настроения (29\%), разАвоение личности (27\%), галмюцинации (17\%);

- барьеры Аля обращения за психиатрической помощью со стороны роАственников иАи знакомых человека с явными признаками шизосррении таковы: $38 \%$ опрошенных отметили страх огласки - они опасаются, что в случае визита к врачу о болезни узнают знакомые $29 \%$ респонАентов-роАственников боятся отправки больного шизодрренией в интернат или больницу.

В опросе ВЦИОМ приняли участие россияне в возрасте от 18 ^ет. Мето опроса - телефонное интервью по стратифоцированной Авух основной случайной выборке стационарных и мобильных номеров объемом 1600 респонАентов. Аля Аанной выборки максимальный размер ошибки с вероятностью 95\% не превышает 2,5\%. 